\title{
Holland's SDS Applied to Chinese College Students: A Revisit to Cross-Culture Adaptation
}

\author{
Jin Kong \\ Nanjing Tech University \\ Nanjing 211800, China \\ E-mail: kongjin2000@126.com
}

Yonghong Jade $\mathrm{Xu}$ (Corresponding author)

Department of Counseling, Educational Psychology, and Research

University of Memphis, Ball Hall 100, Memphis, TN 38152, USA

Tel: 1-901-678-5026_E-mail: yxu@memphis.edu

\author{
Hao Zhang \\ Nanjing Tech University \\ Nanjing 211800, China \\ E-mail: zhanghao@njtech.edu.cn
}

Received: March 9, 2016 Accepted: April 18, 2016 Published: May 2, 2016

doi:10.5296/jei.v2i1.9161ＵRL: http://dx.doi.org/10.5296/jei.v2i1.9161

\begin{abstract}
In this study, data collected from 875 college freshman and sophomore students enrolled in a 4-year university in central China are used to examine the applicability and validity of a Chinese version of Holland's Self-Directed Search (SDS) that was adapted in the 1990s. The total sample was randomly divided into two groups. Data from the first half of the sample $\left(\mathrm{n}_{1}\right.$ $=438$ ) were used to analyze the reliability and validity of the adapted SDS, and 52 items were identified for removal due to lack of cross-cultural fit, lack of validity to measure the intended construct, and/or being obsolete due to progress in societal and occupational trends. The SDS before and after item removal were further compared using confirmatory factor analysis with the second half of the sample $\left(\mathrm{n}_{2}=437\right)$. Practical implications of this empirical
\end{abstract}


modification approach are discussed. This study contributes to the literature by extending the current discussion about cross-cultural adaptation of Holland's inventories and by suggesting a methodological approach to improve the reliability and validity of adapted assessment tools.

Keywords: Holland's theory, Self-Directed Search (SDS), Cross-cultural applicability, Assessment tool modification, Vocational counseling in China

\section{Introduction}

Helping students make career decisions is one of the critical functions of higher education institutions. In recent decades, there has been an expanding interest in China in Holland's theory and assessment inventories as many secondary and postsecondary education institutions started to search for tools to help students' career planning. In fact, the number of publications that offer anecdotal or empirical discussion of using Holland's theories and inventories to guide the career choices of Chinese youths has been on the rise (e.g., Long, Adams, \& Tracey, 2005; Long \& Peng, 2000; Long, Peng, \& Zheng, 1996; Tang, 2001; Tien, 2009; Zhang, Kong, Chen, \& Li, 2014). Growing with the international recognition of Holland's theory and career interest assessment are also serious concerns. First are the challenges in adapting measures and assessment tools across culture. Cross-cultural applications run the risk that there may be substantive differences in the underlying meaning ascribed by each culture to the methods and assessment items, leading to differences in the validity and structural properties of the measures (Rounds \& Tracey, 1996; Tinsley, 1992).

Second, the lapse of time adds another complication. Holland's assessment tools were initially developed over half century ago. Since then, rapid development in science and technology has transformed the educational and occupational systems (Bullock et al., 2010; Tien, 2010). Even though there have been updates to Holland's assessment inventories, continuing examination is necessary to validate the assessment items, especially on the inventories that have been in place for decades. Within this context, this study uses a sample of college students from a university in mainland China to examine an adapted version of Holland's Self-Directed Search (SDS, 1994), and proposes empirical-based modifications to improve its construct validity while maintaining faithful confirmation to the theoretical underpinning of the instrument.

\section{Review of Literature}

\subsection{Holland's Theories and Typology}

The core to Holland's theory's is the categorization of six personality types: Realistic, Investigative, Artistic, Social, Enterprising, and Conventional (RIASEC), and each type is characterized by a constellation of characteristics, interests, beliefs, abilities, values, and preferred activities (Nauta, 2010). Holland $(1973,1997)$ illustrated the structural relations among the types in a circular structure of R-I-A-S-E-C (the hexagonal model). The types that are more proximate in the hexagon are supposed to be more similar and share stronger psychological resemblance than types that are more distant (Holland, 1997; Nauta, 2010; Rounds \& Tracey, 1996). During the last few decades, Holland's theory and model have 
contributed in innumerable and significant ways to generating critical knowledge related to career development, assessment, and practice (Nauta, 2010; Rounds \& Tracey, 1996).

The influence of Holland's model grew even stronger when he and colleagues classified occupations using the RIASEC types (Gottfredson \& Holland, 1996; Holland, 1975, 1978), which permit individuals to explore academic majors, occupations, and careers that are congruent with their personalities (Nauta, 2010). By classifying both personality types and the environments, Holland's theory highlights the importance of one's personality being congruent with his or her environment. To date, Holland's RIASEC typology may be the most dominant conceptual model in vocational interest assessment. For instance, in addition to the assessment scales initially proposed by Holland himself (e.g., Vocational Preference Inventory [VPI], Holland, 1985; the Self-Directed Search [SDS], Holland, Fritzsche, \& Powell, 1994; and the Position Classification Inventory [PCI], Gottfredson \& Holland, 1991), there are other well-known measures, such as Strong Interest Inventory (Hansen \& Campbell, 1985), Career Decision-Making Interest Survey (Harrington \& O'Shea, 1993), and Career Assessment Inventory (Johansson, 1986), that were constructed based on Holland's RIASEC model of personalities. Holland's typology is also the theoretical backbone of major vocational assessment programs such as the American College Testing Program (1988) and the United States Employment Service (U.S. Department of Labor, 1979). According to Ruff, Reardon, and Bertoch (2008), Holland's theory and models have appeared in 197 different journals in countries around the world and Holland's RIASEC typology and related applications have been cited over 1,600 times in the literature from 1953 to early 2007 (Bullock et al., 2010).

\subsection{Cross-Cultural Applicability of Holland's RIASEC Typology}

Given the popularity and widespread influence of Holland's theory, model, and assessment inventories, it is not surprising that researchers and practitioners outside the U.S. have worked to adapt his RIASEC model and related assessment tools with the anticipation that they can be useful in investigating vocational interests in different populations (Bullock et al., 2010; Rounds \& Tracey, 1996). For instance, Holland's Self-Directed Search (SDS) has been translated into more than 30 languages (Bullock et al., 2010). Most of Holland's inventories have been adapted to studying young people's occupational interests in other countries, such as SDS in Croatia (Šverko \& Babarovic, 2006) and in Hong Kong (Leung \& Hou, 2005), Personal Globe Inventory (PGI) in Japan (Tracey, 2002), Vocational Preference Inventory (VPI) in India (Leong, Austin, Sekaran, \& Komarraju, 1998), and Strong Interest Inventory (SII) in Korea (Tak, 2004), just to name a few examples.

Nonetheless, empirical research has yielded inconsistent findings regarding the generalizability of Holland's model and inventories (Bullock et al., 2010; Long et al., 2005). On the one hand, some researchers (e.g., Hansen, 1987; Holland, 1985; Yu \& Alvi, 1996) provided evidence that Holland's model captures the structure of interests of international and cross-cultural populations almost as well as it does for White western test-takers (Bullock et al., 2010). On the other hand, Rounds and Tracey (1996) used a meta-analysis to show the lack of consistent support to Holland's structural specification of the RIASEC types, and 
argued that the meaning, interpretations, and intercorrelations of the six types may have substantial variations across cultures. At the minimum, the lack of consistency supports Ben-Porath's (1990) argument that it is important for cross-cultural researchers to investigate construct validity by ascertaining whether the interpretations associated with an inventory developed in the United States can validly be used in another culture.

\subsection{Holland's Assessments in China}

Research and applications of Holland's model and assessment inventories have been growing in China (e.g., Chen, 2006; Long et al., 1996; Long \& Peng, 2000; Tang, 2001; Tien, 2009; C. S. Wong \& P. M. Wong, 2006; Yang, Stokes, \& Hui, 2005), and researchers are aware of the complications related to cross-cultural fit of the RIASEC model due to drastically different cultural and social settings. For instance, Farh et al. (1998) found that the circular RIASEC structure did not fit as well to a sample in Hong Kong as it did to American samples. Rounds and Tracey (1996) found a similar lack of fit in Taiwanese samples. Yang and colleagues (2005) conducted comparisons between two different Chinese samples. They ran confirmatory factor analyses to evaluate Holland's $(1973,1985,1997)$ structural hypotheses with SDS (Holland, 1994) and suggested that the circumplex model was generally not supported for Chinese people.

A few researchers have tried to localize career interest assessment by creating their own inventories based on Holland's RIASEC coding system (e.g., Fang et al., 1996; Tien, 2013; C. S. Wong \& P. M. Wong, 2006), while others (e.g., Chen, 2006; Long et al., 1996) took steps to alter the original U.S. version of an instrument to address the differences in cultural and occupational meanings in items used in Holland's assessments. In mainland China, one of the most popular career interest assessment inventories is the Chinese adaptation of the SDS, which was translated and introduced in the early 1990s (Long, 1991) and later modified by Long and colleagues (1996) based on the social, cultural, and occupational structure in China to better serve the local population. In the modification, the original metric structure of the RIASEC model was kept as well as the subscales measuring activities, competence, and occupational interests within each of the six types, thus maintaining the eighteen ( 6 by $3=18$ ) clusters of items along with the self-estimation ratings at the end. Nonetheless, the number of items within each cluster was reduced to 10 , and items that were judged not applicable to Chinese population were either modified or replaced. For instance, an item on Holland's original SDS, "Fill out income tax forms" was removed because "income tax forms" was an unknown term to Chinese back in the 1990. Another example of localization was the modification of the original item "I can do painting, watercolor, or sculpture," into "I can do painting, drawing, or calligraphy" to reflect the fact that calligraphy was a common form of art in China.

The popularity of the adapted version of SDS has been increasing with people's rapidly growing interest in career interest assessment. For instance, the adapted SDS has been used in a study to establish a system that match the RIASEC personality types with college majors in China (Long \& Peng, 2000). In another study, the SDS was used to examine college students' occupational choices (Chen, 2006). Recently, the adapted SDS was used to investigate the 
occupational interests of a new generation of college students (Zhang et al., 2014). As a matter of fact, a Google search of “Holland's SDS” in Chinese (霍兰德自我职业选择测验) yielded roughly 115,000 items, many of which provide free access to the adapted inventory and self-directed interpretation of the assessment results.

\section{Research Objective}

The growing literature demonstrates that the influence of the RIASEC model has been increasing in many countries, including China. A key issue for cross-culture application of assessment inventories is the need to examine the construct validity and generalizability of a given instrument (Tinsley, 1992). To investigate construct validity, the first step is to ascertain whether the items on a translated instrument from the United States, or on a modified version for local application can validly measure the constructs that are intended to be measured (Long et al., 2005). In this study, we focus on the Chinese adaptation of the SDS to illustrate issues to be considered in inventory localization. Additionally, we take a step further from previous studies on Holland's cross-cultural applicability to explore an empirical approach that improves an inventory by identifying and removing items that appear not to appropriately measure the underlying constructs due to either cultural differences or obsoleteness.

\section{Methods}

\subsection{Participants}

The participants in this study were freshman and sophomore students enrolled in a 4-year university in central China. Among a total of 5,933 students (36\% of which are females) at the two class levels, 1,073 responded to the 180-item survey of Self-Directed Search (SDS), which resulted in a final sample of 875 with complete and valid answers. As such, the final response rate was at $14.7 \%$. The 875 respondents consisted of $39.5 \%$ males and $60.5 \%$ females and ranged between 16 and 20 years in age. It is obvious that female students had a higher likelihood of completing the survey than males, a phenomenon commonly observed in survey studies (Porter \& Whitcomb, 2005; Sax, Gilmartin, \& Bryant, 2003). Distribution of respondents was roughly even in STEM (science, technology, engineering, and mathematics, $\mathrm{n}=456)$ and non-STEM majors $(\mathrm{n}=419)$.

\subsection{Instrument}

The Chinese version of Holland's SDS (Long et al., 1996; Lu, Li, \& Tang, 1996) was the primary survey instrument used in this study, along with added questions about students' background information (e.g., age, major, and gender). This adapted SDS maintains the original structure of the Holland's RIASEC model, with a total of 180 items measuring activity, competence, and occupational interests in each of the six interest categories: Realistic (R), Investigative (I), Artistic (A), Social (S), Enterprising (E), and Conventional (C). The response format was modified into a Likert scale (i.e., strongly like [5], somewhat like [4], indifference [3], somewhat dislike [2], and strongly dislike [1]) in order to improve the measurement accuracy (Chen, 2006; Lu et al., 1996). For every respondent, eighteen cluster scores were generated (RIASEC types by subscales of activity, competence, and 
occupational interests) by averaging the responses to individual items belonging to the same cluster. Respondents' self-estimation rating scores were not studied due to its unique data structure. There is extensive reliability and validity support for the scales (Nauta, 2010). In this study, the coefficient alphas for the six personality types were $.93, .89, .91, .87, .90$ and 87 , respectively.

\subsection{Data Collection}

Data collection took place in May 2013 and was part of a project titled "Investigation of Career Preference and Academic Interest." Call for response to the SDS survey online was initiated by the university's Provost Office, and conveyed to all freshman and sophomore students in 56 majors through college and departmental administrative staff. Students were informed about the purpose of the study before a link to the online survey was provided. It was made clear that response to the survey was completely voluntary. The summary report generated from the SDS would be made available to individual respondents who were interested in the evaluation, but no material compensation was offered in any format.

\subsection{Analytical Procedures}

Three steps were taken to fulfill the research objectives of this study. First, the total sample of 875 college students was randomly divided into two groups. Data from half of the sample $\left(n_{1}\right.$ $=438$ ) were used for exploratory factor analysis (EFA). Specifically, an EFA was done within each of the eighteen clusters of items (Table 1) in accordance with the conceptual structure of the SDS, using principal component extraction and restricting the number of extracted factors to one. The items with the lowest loading on the extracted factor would be considered for removal, and the values of Cronbach's alpha of the cluster before and after the item removal were compared. An item would be removed only if the resulting reduction in internal reliability, if any, was no greater than .03. After the EFA-guided item removals from the subscales, 128 items remained and the SDS was considered as a simplified and more updated and culturally-suitable version to measure current Chinese college students' vocational interests.

Second, both the full and the simplified versions of the adapted SDS were tested with data from the second half of the sample $\left(\mathrm{n}_{2}=437\right)$ using confirmatory factor analysis (CFA). The two models were to be compared based on goodness of fit indices including model $\chi^{2}$, RMSEA, SRMR, and CFI. With the goal that only unsuitable items should be removed, the simplified version was expected to have better model fit indices than that of the full version; particularly, the model $\chi^{2}$ should show significant reduction. Finally in the last step, all 875 respondents were categorized into one of the RIASEC types in accordance with their highest score among the six subscales. The categorization with the 180-item SDS and the simplified128-item SDS were compared to offer evidence of reliability and concurrent validity.

\section{Results}

Descriptive analysis of the data indicated that $26.5 \%$ of the respondents (232) were categorized as $\mathrm{S}$ based on their scores from the SDS test, following by $21.7 \%$ of $\mathrm{A}$, and 
$17.8 \%$ of I. The other three categories, E, C, and R, accounted for approximately $15 \%, 13 \%$, and $6 \%$ of the sample, respectively. Significant differences existed between genders $\left(\chi^{2}=\right.$ $118.18, \mathrm{p}<.001$ ), with girls being more likely in the categories of $\mathrm{A}, \mathrm{S}$, and $\mathrm{C}$, and boys being significantly more likely in I, E, and S. The gendered pattern of distribution is consistent with that of previous studies (Creed et al., 2009).

\subsection{EFA and Item Identified for Removal}

The 875 respondents were randomly divided into two groups. Using data from the first half $\left(n_{1}=438\right)$, scree plots in the EFAs confirmed that there was only one underlying factor within each of the item clusters. As shown in Table 1, in the majority of the subscales, three items were identified for removal based on their factor loading; in a few cases, either two or four items were removed. The decision to remove an item was based on three guidelines: 1) the factor loading of an item was among the lowest in the subscale; 2) there was a perceivable gap between the factor loading of the item and the items with relative higher loadings; and 3) removing the item would not reduce the Cronbach's alpha of the cluster over a magnitude of .03. Altogether, fifty-two items were removed and the total number of items was reduced to 128 . With roughly one third reduction in number of items, the Cronbach's alpha of the scales measuring the RIASEC types had little changes from the full version and the values were $.93, .88, .89, .85, .88$ and .87 , respectively.

Table 1. Items identified for Removal (Items with Chinese translation indicate modification and/or replacement of items on the original Holland's SDS inventory)

\begin{tabular}{|c|c|c|c|}
\hline \multirow{2}{*}{ Subscale } & \multirow{2}{*}{ Items for Removal (EFA factor loading) } & \multicolumn{2}{|c|}{ Internal Reliability } \\
\hline & & Before & After \\
\hline Realistic activities (R1) & $\begin{array}{l}\text { Build things with wood }(.545) \\
\text { Operate motorized machines or equipment }(.356) \\
\text { Take a Mechanical drawing course }(.596)\end{array}$ & .884 & .898 \\
\hline $\begin{array}{l}\text { Realistic competence } \\
\text { (R2) }\end{array}$ & $\begin{array}{l}\text { I can use a multimeter. 知道万用表的使用方法 } \\
(.670) \\
\text { I have operated power tools such as drill press, } \\
\text { grinder, or sewing machines (.730) } \\
\text { I can refurbish furniture or woodwork (.666) }\end{array}$ & .925 & .921 \\
\hline $\begin{array}{l}\text { Realistic Occupational } \\
\text { interests }(\mathrm{R} 3)\end{array}$ & $\begin{array}{l}\text { Wildlife expert 野生动物专家 (.220) } \\
\text { Radio Mechanic (.357) } \\
\text { Gardener 园艺师 (-.002) }\end{array}$ & .652 & .721 \\
\hline $\begin{array}{l}\text { Investigative activities } \\
\text { (I1) }\end{array}$ & $\begin{array}{l}\text { Improve fruit varieties/cultivate new fruit types. 想 } \\
\text { 改良水果品种/培育新的水果 }(.532) \\
\text { Study a scholarly or technical problems }(.524)\end{array}$ & .840 & .832 \\
\hline
\end{tabular}




\begin{tabular}{|c|c|c|c|}
\hline $\begin{array}{l}\text { Investigative } \\
\text { competence (I2) }\end{array}$ & $\begin{array}{l}\text { I can name three kinds of food rich in protein. 能够 } \\
\text { 列举三种蛋白质多的食品 }(.459) \\
\text { I can identify three constellations. 能找到三个星座 } \\
(.312) \\
\text { I can use computer to study a scientific problem } \\
(.485) \\
\text { I attend professional conferences. 经常参加学术会 } \\
\text { 议 }(.473)\end{array}$ & .795 & .812 \\
\hline $\begin{array}{l}\text { Investigative } \\
\text { occupational interests } \\
\text { (I3) }\end{array}$ & $\begin{array}{l}\text { Anthropologist }(.548) \\
\text { Mathematician 数学学者 }(.527) \\
\text { Writer of scientific articles (.446) }\end{array}$ & .793 & .768 \\
\hline Artistic activities (A1) & $\begin{array}{l}\text { Sketch, draw, or paint (.449) } \\
\text { Read novels or plays 喜欢看小说/读剧本 (.476) } \\
\text { Practice calligraphy 喜欢练习书法 }(.543)\end{array}$ & .829 & .826 \\
\hline Artistic activities (A2) & $\begin{array}{l}\text { I can act in a play }(.592) \\
\text { I can write a speech }(.561)\end{array}$ & .860 & .850 \\
\hline $\begin{array}{l}\text { Artistic occupational } \\
\text { interests (A3) }\end{array}$ & $\begin{array}{l}\text { Photographer (摄影家) (.523) } \\
\text { Journalist (.558) } \\
\text { Artist 画家/书法家 (.554) }\end{array}$ & .846 & .834 \\
\hline Social activities (S1) & $\begin{array}{l}\text { Take care of children (喜欢照顾儿童) (.449) } \\
\text { Take field trip with friends 喜欢和大家一起出去郊 } \\
\text { 游 (.370) } \\
\text { Watch or participate in sport games and activities 喜 } \\
\text { 欢观看或参加体育比赛和运动会 }(.471)\end{array}$ & .804 & .815 \\
\hline Social competence (S2) & $\begin{array}{l}\text { I am good at explaining things to others }(.554) \\
\text { I find it easy to talk with all kinds of people }(.520) \\
\text { Help take care of patients 帮助护理病人和伤员 } \\
(.564)\end{array}$ & .827 & .800 \\
\hline $\begin{array}{l}\text { Social occupational } \\
\text { interests }(\mathrm{S} 3)\end{array}$ & $\begin{array}{l}\text { Rehabilitant counselor }(.310) \\
\text { Sports coach 体育教练 }(.155) \\
\text { Tourist guide 导游 }(.459)\end{array}$ & .662 & .674 \\
\hline $\begin{array}{l}\text { Enterprising activities } \\
\text { (E1) }\end{array}$ & $\begin{array}{l}\text { Try to persuade others 希望说服鼓动他人 (.495) } \\
\text { Operate my own service or business 喜欢卖东西 } \\
(.472) \\
\text { Talk about politics 喜欢谈论政治 }(.583)\end{array}$ & .840 & .831 \\
\hline $\begin{array}{l}\text { Enterprising } \\
\text { competence (E2) }\end{array}$ & $\begin{array}{l}\text { I was a leader of a social club or group 曾作为俱乐 } \\
\text { 部或社团的负责人 (.587) }\end{array}$ & .859 & .836 \\
\hline
\end{tabular}




\begin{tabular}{|c|c|c|c|}
\hline & $\begin{array}{l}\text { I once was a good leader in student groups 担任过学 } \\
\text { 生干部并且干得不错 }(.618) \\
\text { I am an ambitious and energetic person 做事充满活 } \\
\text { 力和热情 }(.621)\end{array}$ & & \\
\hline $\begin{array}{l}\text { Enterprising } \\
\text { occupational interests } \\
\text { (E3) }\end{array}$ & $\begin{array}{l}\text { TV program producer 电视片编制人 (.412) } \\
\text { Organizer of sport programs 体育活动主办者 } \\
(.378) \\
\text { Small business owner }(.516)\end{array}$ & .766 & .764 \\
\hline $\begin{array}{l}\text { Conventional activities } \\
\text { (C1) }\end{array}$ & $\begin{array}{l}\text { Clean and organize room and desktop 喜欢整理好桌 } \\
\text { 面和房间 }(.529) \\
\text { Keep detailed records of expenses (.526) } \\
\text { Take an information processing course 想参加情报 } \\
\text { 処理培训班 }(.585)\end{array}$ & .844 & .830 \\
\hline $\begin{array}{l}\text { Conventional } \\
\text { competence }(\mathrm{C} 2)\end{array}$ & $\begin{array}{l}\text { I can type in Chinese fluently 会熟练地打印中文 } \\
(.533) \\
\text { I can use a typewriter or copier machine 会用外文打 } \\
\text { 字机或复印机 (.474) } \\
\text { I can use an abacus 会用算盘 (.309) } \\
\text { I can enter information at a computer terminal 能使 } \\
\text { 用计算机 (.450) }\end{array}$ & .765 & .773 \\
\hline $\begin{array}{l}\text { Conventional } \\
\text { occupational interests } \\
\text { (C3) }\end{array}$ & $\begin{array}{l}\text { Computer operator }(.367) \\
\text { Typewriter clerk 打字员 }(.484)\end{array}$ & .827 & .834 \\
\hline
\end{tabular}

\subsection{CFA and Validation of the Simplified Version of the Inventory}

Both the full (180-item) and the simplified (128-item) versions of the SDS were examined with a CFA model using data from the remaining half of the sample $\left(n_{2}=437\right)$. As shown in Table 2, the two versions had acceptable fit indices, but the simplified version had improved fit indices by all counts. According to the literature on CFA (Kline, 2010), the guidelines for good model fit indices are RMSEA $<.08$, SRMR $<.06$, and normed $\chi^{2}<4$, and lower $\chi^{2}$ and AIC values are always desirable. Not only did the simplified version have lower RMSEA, SRMR, and AIC values, it also reduced the model $\chi^{2}$ by 20265.80 , which was statistically significant at $\mathrm{p}<.001$ with a degree freedom difference of 8056 . The CFA results suggest that the simplified version of the SDS has a better validity when applied to Chinese college students. 
Table 2. CFA model fit indices to compare the original and simplified versions of the inventory

\begin{tabular}{|l|l|l|l|l|l|l|}
\hline & Model $\chi^{2}(d f)$ & Normed $\chi^{2}$ & RMSEA $(90 \%$ CI $)$ & CFI & SRMR & AIC \\
\hline Original & $35992.36(15777)$ & 2.28 & $.054(.053, .055)$ & .92 & .075 & 37018.36 \\
\hline Simplified & $15726.56(7721)$ & 2.04 & $.049(.048, .050)$ & .93 & .066 & 16540.56 \\
\hline
\end{tabular}

\subsection{Consistency in Interest Categorization}

All 875 respondents were categorized into one of the six types in accordance with their highest score among the six RIASEC subscales. As shown in Table 3, 81\% $(n=707)$ of them had the same categorization on the full and simplified SDS inventories. Three groups on the full SDS, R $(n=67), A(n=123)$, and $E(n=84)$, had $67.2 \%, 77.2 \%$, and $76.2 \%$, partly due to their relatively small group sizes, and partly due to the number of respondents shifted to adjacent categories. It is worth noting that, 23 students who were the S type by the full SDS were now classified as $\mathrm{C}$ by the simplified version; and another 23 and 12 were also moved from $\mathrm{S}$ type to I or $\mathrm{E}$ on the simplified version, respectively. These shifts in categorization point to the $\mathrm{S}$ type as the most unstable categorization based on the 180-item SDS inventory.

Table 3. Categorization of RIASEC types by original and simplified SDS

\begin{tabular}{|c|c|c|c|c|c|c|c|c|c|c|c|c|c|c|}
\hline \multirow{3}{*}{$\begin{array}{l}\text { Full } \\
\text { SDS }\end{array}$} & \multicolumn{14}{|c|}{ Simplified SDS } \\
\hline & \multicolumn{2}{|c|}{$\mathrm{R}$} & \multicolumn{2}{|c|}{ I } & \multicolumn{2}{|c|}{ A } & \multicolumn{2}{|c|}{ S } & \multicolumn{2}{|c|}{$\mathrm{E}$} & \multicolumn{2}{|c|}{$\mathrm{C}$} & \multicolumn{2}{|c|}{ Table Total } \\
\hline & Count & Row\% & Count & Row\% & Count & Row\% & Count & Row\% & Count & Row\% & Count & Row\% & Count & $\mathrm{Col} \%$ \\
\hline $\mathrm{R}$ & 45 & $67.2 \%$ & 15 & $22.4 \%$ & & & 2 & $3.0 \%$ & 4 & $6.0 \%$ & 1 & $1.5 \%$ & 67 & $7.7 \%$ \\
\hline I & 2 & $1.6 \%$ & 114 & $90.5 \%$ & 1 & $0.8 \%$ & 8 & $6.3 \%$ & & & 1 & $0.8 \%$ & 126 & $14.4 \%$ \\
\hline A & 1 & $0.8 \%$ & 4 & $3.3 \%$ & 95 & $77.2 \%$ & 16 & $13.0 \%$ & 2 & $1.6 \%$ & 5 & $4.1 \%$ & 123 & $14.1 \%$ \\
\hline S & 8 & $2.1 \%$ & 23 & $6.0 \%$ & 4 & $1.0 \%$ & 314 & $81.8 \%$ & 12 & $3.1 \%$ & 23 & $6.0 \%$ & 384 & $43.9 \%$ \\
\hline E & 3 & $3.6 \%$ & 2 & $2.4 \%$ & 1 & $1.2 \%$ & 10 & $11.9 \%$ & 64 & $76.2 \%$ & 4 & $4.8 \%$ & 84 & $9.6 \%$ \\
\hline $\mathrm{C}$ & 2 & $2.2 \%$ & 3 & $3.3 \%$ & & & 6 & $6.6 \%$ & 5 & $5.5 \%$ & 75 & $82.4 \%$ & 91 & $10.4 \%$ \\
\hline Total & 61 & $7.0 \%$ & 161 & $18.4 \%$ & 101 & $11.5 \%$ & 356 & $40.7 \%$ & 87 & $9.9 \%$ & 109 & $12.5 \%$ & 875 & $100.0 \%$ \\
\hline
\end{tabular}




\section{Discussion}

The purpose of this study is to improve the validity of an adapted Chinese version of Holland's SDS inventories by empirically identifying and removing items that may not properly measure the underlying constructs. Without modifying the metric structure of the instrument, the conceptual framework for the RIASEC types remained unchanged. Nonetheless, EFA of the measurement items led to removal of 2-4 items from a total of 10 items in every cluster, and the simplified version of SDS showed better goodness of fit indices than the original version of SDS when tested with a different sample of respondents.

\subsection{Items Identified for Removal}

Careful examination of the removed items revealed that the vast majority of items were removed for 1) lack of cross-cultural generalizability, 2) lack of validity to measure the intended construct, 3) being obsolete due to progress in societal and occupational trends, or 4) a combination of the aforementioned three factors. For instance, "Build things with wood" and "refurbish furniture or woodwork" were handy activities not commonly known to most Chinese youth, and "Rehabilitant counselor" was an occupation almost unheard of in Chinese culture. They were identified for removal primarily due to lack of cross-cultural generalizability.

During the process of localizing the SDS inventory, the researchers (Long et al., 1996; Lu, Li, \& Tang, 1996) had used new items to replace those that were believed to be culturally unfitted. However, some of the added items may have failed to measure the intended construct. For example, "I attend professional conferences" was added to measure Investigative competence; unfortunately "attending professional conferences" happened to be a concept novel to the majority of students in high schools and colleges. The usability of this item for investigating vocational interest is especially questionable given the fact that in Chinahigh school students must declare a major prior to college entrance (Tang, 2001). Disconnection between the item and the underlying construct also caused the removal of items in other places, such as "I once was a good leader in student groups" in Enterprising competence and "Wildlife expert" in the Realistic occupations.

Also, the Chinese version of SDS was modified and published in 1996, and many items have become outdated during the past two decades. Examples of this are commonly found in items measuring Conventional type, including abilities such as "I can enter information at a computer terminal" and "I can use an abacus," and occupations such as "Computer operator" and "Typewriter clerk."

\subsection{Issues in Cross-Cultural Validity}

By identifying and removing the items that no longer properly measuring the underlying constructs, the simplified version of the SDS had better validity measures according to the CFA results. The simplified version keeps the same RIASEC structure, while using a few items to measure the underlying construct. Over $80 \%$ of the samples had consistent categorization between the 180-item and 128-item versions of SDS. Nonetheless, comparisons between the results of the two versions generate questions about identifying the 
Social type. A comparison of items on Holland's original SDS and the Chinese version revealed that, among the six RIASEC types, the most drastic changes were made to items measuring Social activities, competence, and occupational interests. The speculation is that there are different interpretations of "Social" type in the U.S. and Chinese cultures. As reflected in Holland's SDS, Social activities and occupations are driven primarily by interests in providing services to the community (e.g., being teachers, counselors, therapists, and volunteers); whereas in China, the word "social" has its focus on interest or activities in interacting with a large groups of people. As such, the modified version has items about participating in social groups, clubs, and sports events, and interests in being a tourist guide, or government employee. Such modifications, even though based on the intent to improve cross-cultural applicability, resulted in items that failed to measure the underlying construct. For the same reason, the modified and/or replaced items in the Social category may have led to inaccurate categorization of individuals by the 180-item version. Once those problematic items were identified and removed, substantial changes were observed in the Social categorization between the full and the simplified versions of the SDS.

\subsection{Practical Implications}

There are a few things to take away from this study. First, more systematic and well-thought steps are needed when localizing or adapting an existing Holland's inventory into a different culture. In this case, the 180-item SDS had great reliability measures as indicated by the high Cronbach's alpha values. Still, many items had less than sufficient loading to the underlying constructs as shown in both the EFA and CFA. The findings of this study suggest that examination of the quality of an instrument should go beyond simple reliability measures, and it is always necessary to check on additional information about content validity and construct validity. Second, statistical analysis as well as input from domain experts can both contribute to improving an existing inventory to make it culturally more applicable. The initial adaptation of the original Holland's SDS was based on modifications made by Chinese experts' evaluations and judgments. Even so, well-designed statistical examination of the adapted instrument, as illustrated in this study, helps to further elaborate the construct grounding of the items.

Third, monitoring the applicability of existing measurement instruments should be an ongoing process, especially in a society that is undergoing rapid cultural and occupational changes. As shown in this study, a number of items have already gone obsolete in the Chinese version of the SDS adapted two decades ago, a time during which Chinese people experienced great economic and cultural progress. Removal or replacement of outdated items would improve the validity and continuing applicability of the assessment inventory. Last but not least, as illustrated by evidence in this study, fidelity to the grounding theoretical framework can be maintained by an assessment tool of fewer items. Relative to a lengthy instrument, individuals are more likely to complete a survey of fewer items, and to do so with greater care and attention (Deutskens et al., 2004). This study demonstrated methodological steps to simplify a survey instrument while assuring its reliability and validity, which will be useful in future research on survey design and improvement. 


\subsection{Limitations and Future Directions}

The sample of this study consisted of volunteering freshman and sophomore students from one four-year college in China. The sample was not statistically representative to claim generalizability of the findings; and we were unable to further evaluate how the sample affects construct and predictive validity of the simplified instrument due to limited data availability. Thus, further examination of the simplified SDS is needed before applying it to empirical research and career counseling practice. Also, the focus of this study is the reliability and validity of an adapted SDS. What remains unexamined 啊热 the internal relations among the RIASEC types, represented by a hexagon, that specifies the structural relationships of the six different personality types (Holland, 1985, 1997). Given the empirical evidence that Holland's circular relationships differed significantly across countries (Bullock et al., 2010; Farh et al., 1998), the structural property of the SDS, as measured by the simplified version, should be tested in future research. It is also worth noting that inaccurate Chinese translation of some of the items may contribute to their misfits and subsequent removal in the analyses. If possible, it would be interesting to replicate this study with data collected from a comparable sample of American college students using Holland's original SDS, and comparison between the two populations will help better understand issues related to cross-cultural applicability.

\section{Conclusion}

Holland's theory, the RIASEC model, and associated assessment tools help individuals better understand their own personality and provide them the guidance in identifying skills, occupations, and work environments in which they are more likely to persist and be successful (Bullock et al., 2010). This study contributes to the literature by extending the discussion about the cross-cultural adaptation of Holland's assessment tools and by suggesting methodological approaches to improve the reliability and validity of an adapted inventory. The findings hold promise for scholars, researchers, and practitioners in vocational psychology and guidance in China because theoretically grounded schemes and valid assessment tools for identifying vocational personalities and classifying occupations will become more useful as China's economy becomes more urban and market-driven (Bullock et al., 2010). In the long run, we hope this study will contribute to assuring that Holland's theory, model, and assessment tools are appropriately adapted and used in different cultural settings, and to increasing the knowledge on how to address the evolving occupational needs of individuals.

\section{References}

American College Testing Program. (1977). Handbook for the ACT career planning program. Iowa City, IA: Author.

Ben-Porath, Y. S. (1990). Cross-cultural assessment of personality: The case for replicatory factor analysis. In J. N. Butcher \& C. D. Spielberger (Eds.), Advances in personality assessment (Vol. 8, pp. 27-48). Hillsdale, NJ: Erlbaum.

Bullock, E. E., Andrews, L., Braud, J., \& Reardon, R. C. (2010). Holland's theory in an 
international context: Applicability of RIASEC structure and assessments. Career Planning \& Adult Development Journal, 25(4), 29-58.

Chen, R. (2006). 自我职业选择测验量表(SDS) 的修订及大学生职业选择特点研究 (Doctoral dissertation, 西南大学, China).

Creed, P. A., Wong, O. Y., \& Hood, M. (2009). Career decision-making, career barriers and occupational aspirations in Chinese adolescents. International Journal for Educational and Vocational Guidance, 9, 189-203. http://dx.doi.org/10.1007/s10775-009-9165-0

Deutskens, E., de Ruyter, K., Wetzels, M., \& Oosterveld, P. (2004). Response rate and response quality of internet-based surveys: An experimental study. Marketing Letters, 15, 21-36. http://dx.doi.org/10.1023/B:MARK.0000021968.86465.00

Fang, L. L., Bai, L. G., \&Lin, W. Q. (1996). Construction of the Chinese Vocational Interest Inventory of Holland Type. Acta Psychologica Sinica, 31, 113-119.

Farh, J. L., Leong, F. T. L., \& Law, K. S. (1998). Cross-cultural validity of Holland's model in Hong Kong. Journal of Vocational Behavior, 52(3), 425-440. http://dx.doi.org/10.1006/jvbe.1997.1631

Gottfredson, G. D., \& Holland, J. L. (1991). The Position Classification Inventory: Professional manual. Odessa, FL: Psychological Assessment Resources.

Gottfredson, G. D., \& Holland, J. L. (1996). Dictionary of Holland occupational codes (3rd ed.). Odessa, FL: Psychological Assessment Resources.

Hansen, J. C. (1987). Cross-cultural research on vocational interests. Measurement and Evaluation in Counseling and Development, 19, 163-176.

Hansen, J. C., \& Campbell, D. P. (1985). Manual for the Strong Interest Inventory (4th ed.). Palo Alto, CA: Consulting Psychologists Press.

Harrington, T. F., \& O'Shea, A. T. (1993). The Harrington-O'Shea Career Decision-Making System Revised manual. Circle Pines, MN: American Guidance Service.

Holland, J. L. (1973). Making vocational choices. Englewood Cliffs, NJ: Prentice-Hall.

Holland, J. L. (1978). The Occupations Finder. Odessa, FL: Psychological Assessment Resources.

Holland, J. L. (1985). Manual for the Vocational Preference Inventory. Odessa, FL: Psychological Assessment Resources.

Holland, J. L. (1994). The Self-Directed Search (4th ed.). Odessa, FL: Psychological Assessment Resources.

Holland, J. L. (1997). Making vocational choices: A theory of vocational personalities and work environments (3rd ed.). Odessa, FL: Psychological Assessment Resources.

Holland, J. L., Fritzsche, B. A., \& Powell, A. B. (1994). The Self-Directed Search technical 
manual. Odessa, FL: Psychological Assessment Resources.

Johansson, C. B. (1986). Career Assessment Inventory: The enhanced version. Minneapolis, $\mathrm{MN}$ : National Computer Systems.

Kline, R. B. (2010). Principles and practice of structural equation modeling (3rd ed.). New York, NY: Guilford Press.

Leong, F. T. L., Austin, J. T., Sekaran, U., \& Komarraju, M. (1998). An evaluation of the cross-cultural validity of Holland's theory: Career choices by workers in India. Journal of Vocational Behavior, 52(3), 441-455. http://dx.doi.org/10.1006/jvbe.1997.1637

Leung, S. A., \& Hou, Z. (2005). The structure of vocational interests among Chinese students. Journal of Career Development, 32(1), 74-90.http://dx.doi.org/10.1177/0894845305277036

Long, L. R. (1991). Development trend of three vocational interest tests. Psychological Science, 1991(3), 59-60.

Long, L. R., Adams, R. S., \& Tracey, J. G. (2005). Generalizability of interest structure to China: Application of the Personal Globe Inventory. Journal of Vocational Behavior, 66, 66-80. http://dx.doi.org/10.1016/j.jvb.2003.12.004

Long, L. R., Peng, P. G., \& Zheng, P. (1996). 自我职业选择测验(SDS)的试用报告. Applied Psychology, 1996(1).

Long, L. R., \& Peng, P. G. (2000). 运用自我职业选择测验(SDS)研制大学专业搜寻表的 初步研究. 心理学报, 4, 453-457.

Lu, R. Y., Li, L., \& Tang, N. Y. (1996). Directions in Vocational Psychology and Counseling. 职业心理与职业指导. 北京: 人民教育出版社.

Nauta, M. M. (2010). The development, evolution, and status of Holland's theory of vocational personalities: Reflections and future directions for counseling psychology. Journal of Counseling Psychology, 57(1), 11-22. http://dx.doi.org/10.1037/a0018213

Porter, S. R., \& Whitcomb, M. E. (2005). Nonresponse in student surveys: The role of demographics, engagement and personality. Research in Higher Education, 46(2), 127-152. http://dx.doi.org/10.1007/s11162-004-1597-2

Rounds, J., \& Tracey, T. J. G. (1996).Cross-cultural structural equivalence of RIASEC models and measures. Journal of Counseling Psychology, 43, 310-329. http://dx.doi.org/10.1037/0022-0167.43.3.310

Ruff, E. A., Reardon, R. C., \& Bertoch, S. C. (June, 2008). Holland's RIASEC theory and applications: Exploring a comprehensive bibliography. Career Convergence. Retrieved from http://www.ncda.org/aws/NCDA/pt/sd/news_article/5483/blank/blank/true

Sax, L. J., Gilmartin, S. K., \& Bryant, A. N. (2003). Assessing response rates and nonresponse bias in web and paper surveys. Research in Higher Education, 44(4), 409-432. http://dx.doi.org/10.1023/A:1024232915870 
Šverko, I., \& Babarovic, T. (2006). The validity of Holland's theory in Croatia. Journal of Career Assessment, 14(4), 490-507.http://dx.doi.org/10.1177/1069072706288940

Tak, J. (2004). Structure of vocational interests for Korean college students. Journal of Career Assessment, 12(3), 298-311. http://dx.doi.org/10.1177/1069072703261555

Tang, M. (2001). Investigation of the structure of vocational interests of Chinese college students. Journal of Career Assessment, $\quad 9, \quad 365-380$. http://dx.doi.org/10.1177/106907270100900404

Tien, S. H. (2009). Cultural encountering: The applicability of Holland's typology in Taiwan. Asian Journal of Counselling, 16(2),193-226.

Tinsley, H. E. A. (Ed.). (1992). Special issue on Holland's theory. Journal of Vocational Behavior, 40(2), 109-110. http://dx.doi.org/10.1016/0001-8791(92)90059-9

Tracey, T. J. G. (2002). Personal Globe Inventory: Measurement of the spherical model of interests and competence beliefs. Journal of Vocational Behavior, 60, 113-172. http://dx.doi.org/10.1006/jvbe.2001.1817

U.S. Department of Labor. (1979). Guide for occupational exploration. Washington, DC: U.S. Government Printing Office.

Wong, C. S., \& Wong, P. M. (2006). Validation of the Wong's career interest assessment questionnaire and the revised Holland's hexagonal model of occupational interests in four Chinese societies. Journal of Career Development, 32(4), 378-393. http://dx.doi.org/10.1177/0894845305284765

Yang, W., Stokes, G. S., \& Hui, C. H. (2005).Cross-cultural validation of Holland's interest structure in Chinese population. Journal of Vocational Behavior, 67(3), 379-396. http://dx.doi.org/10.1016/j.jvb.2004.08.003

Yu, J., \& Alvi, S. A. (1996). A study of Holland's typology in China. Journal of Career Assessment, 4, 245-252. http://dx.doi.org/10.1177/106907279600400301

Zhang, J. M., Kong, J., Chen, T. Y., \& Li, Y. Z. (2014). Chinese college students' interest in their major. Journal of Higher Education Management, 8(4), 112-117.

\section{Copyright Disclaimer}

Copyright for this article is retained by the author(s), with first publication rights granted to the journal.

This is an open-access article distributed under the terms and conditions of the Creative Commons Attribution license (http://creativecommons.org/licenses/by/3.0/). 